\title{
Balkanologie
}

Balkanologie Revue d'études pluridisciplinaires

Vol. IX, n' $1-2 \mid 2005$

Volume IX Numéro 1-2

\section{Roth (Klaus), Hg., Sozialismus : Realitäten und lllusionen. Ethnologische Aspekte der sozialistischen Alltagskultur}

Wien : Verôffentlichungen des Instituts fur Europäische Ethnologie ( ${ }^{\circ}$ 24), 2005, $256 \mathrm{p}$.

\section{Bernard Lory}

\section{(2) OpenEdition}

\section{Journals}

Édition électronique

URL : http://journals.openedition.org/balkanologie/1999

DOI : 10.4000/balkanologie.1999

ISSN : 1965-0582

Éditeur

Association française d'études sur les Balkans (Afebalk)

Édition imprimée

Date de publication : 1 décembre 2005

ISSN : 1279-7952

Référence électronique

Bernard Lory, « Roth (Klaus), Hg., Sozialismus : Realitäten und Illusionen. Ethnologische Aspekte der sozialistischen Alltagskultur », Balkanologie [En ligne], Vol. IX, n 1-2 | 2005, mis en ligne le 14 janvier 2010, consulté le 17 décembre 2020. URL : http://journals.openedition.org/balkanologie/1999 ; DOI : https://doi.org/10.4000/balkanologie.1999

Ce document a été généré automatiquement le 17 décembre 2020.

(C) Tous droits réservés 


\section{Roth (Klaus), Hg., Sozialismus :} Realitäten und lllusionen. Ethnologische Aspekte der sozialistischen Alltagskultur

Wien : Verôffentlichungen des Instituts fur Europäische Ethnologie ( $\mathrm{n}^{\circ}$ 24), 2005, $256 \mathrm{p}$.

\section{Bernard Lory}

\section{RÉFÉRENCE}

Roth (Klaus), Hg., Sozialismus : Realitäten und lllusionen. Ethnologische Aspekte der sozialistischen Alltagskultur, Wien : Verôffentlichungen des Instituts fur Europäische Ethnologie (n²4), 2005, $256 \mathrm{p}$.

1 La période socialiste fait l'objet de réinterprétations idéologiques souvent très partisanes qui tendent à en répandre une vision plus fantasmatique qu'historiquement justifiée. Loin des grandes déclarations de principe, le présent volume s'attache à décrire, aussi précisément que possible un certain nombre d'aspects de la vie quotidienne caractéristiques de cette période de quarante-cinq ans. La plupart des dixhuit études portent sur des cas bulgares, mais aussi sur la Yougoslavie et la République Démocratique Allemande.

2 Le logement est au centre de la réflexion de trois études. Celle de Doroteja Dobreva sur les stratégies mises en œuvre pour la construction d'une maison individuelle dans un village, dans les années 60 et dans les années 80 , est remarquable de clarté dans la mise à plat de l'action "illégale, mais non illégitime » (p. 28) des réseaux de solidarité et de clientélisme. Le phénomène des grands ensembles citadins d'immeubles préfabriqués pose problème : faute d'une véritable méthode d'enquête, les deux études qui leur sont consacrées restent au niveau du discours commun. 
3 Petăr Petrov s'attache à un aspect secondaire, mais révélateur, de l'emprise que le régime socialiste voudrait exercer sur la paysannerie en stimulant la diffusion de livres et de brochures de vulgarisation agronomique, par le biais du réseau des čitalište (maison de la culture) déjà très développé avant 1944. L'étude de cas montre que, malgré des "plans de développement de la lecture », ce genre d'ouvrages ne jouissaient guère des faveurs des paysans, lesquels, tant qu'à faire d'emprunter des livres, choisissaient plutôt des romans. Ženja Pimpireva étudie les documents normatifs concernant les « Maisons de la Culture socialiste ", sortes de salles des fêtes destinées à la célébration des rituels socialistes, en substitution aux rituels coutumiers et aux liturgies religieuses; nous espérons qu'un travail d'enquête fournissant le point de vue des « consommateurs » de ces rituels viendra compléter cette recherche.

4 Milena Benovska-Săbkova s'interroge sur les pratiques de petite corruption à l'égard des enseignants, dont elle trouve trace dès le XIX ${ }^{\text {ème }}$ siècle; dans le contexte de pénurie et de bas salaires du socialisme, elles occupaient une certaine place malgré leur caractère de déviation de la norme socialiste; sur la base d'une trentaine d'entretiens avec des candidats à l'éducation universitaire à Sofia en 1999, elle montre des évolutions contemporaines du même phénomène.

5 Les études sur la famille socialiste et les rapports entre genres occupent un bon tiers du volume. Nous retiendrons celle de Miroslava Malešević qui montre les progrès vers l'égalité des sexes en Yougoslavie durant la Deuxième Guerre mondiale et l'immédiat après-guerre, puis un retour en arrière très prononcé durant la décennie suivante ; la "question féminine " étant considérée comme purement et simplement résolue, les pratiques traditionnelles reprenaient leurs droits. La même problématique est traitée pour la Bulgarie par Ana Luleva, dans une étude remarquable de clarté, qui prend en compte la période pré-socialiste et étudie les évolutions de la législation parallèlement au discours officiellement tenu par le régime, partagé entre sa volonté de faire participer l'ensemble de la main d'œuvre féminine à la production et ses préoccupations d'ordre démographique. Karin Taylor se penche sur la génération accédant à l'âge adulte dans les années 1960-1970 : liberté du choix du partenaire lors de la période d'entre-deux que constituent les études, problèmes de logement pour le jeune couple, relative permissivité à l'égard des relations sexuelles pré-maritales. Jadranka Djordjević examine les droits à l'héritage qu'ont les filles dans la région de Vranje et montre que, malgré l'égalité des droits prévue par la loi socialiste, les pratiques coutumières, qui laissent aux garçons les biens immobiliers, restent prédominantes.

6 Signalons enfin l'article d'Elka Minčeva qui nous aide à comprendre la logique interne qui sous-tendait l'abominable Processus de régénération (la campagne de changement de noms imposé à la minorité turque de Bulgarie en 1984-1985) ; la région de Devin avait joué un rôle pilote car ce processus s'était déroulé en 1970 pour les villages pomaks et en 1975 pour les villages turcs. En 1987, une série de fraternisations entre familles turques d'une part, bulgares ou pomaques de l'autre, y fut organisée de façon officielle, au moyen de rituels mélangeant des aspects de la tradition villageoise et des pratiques festives socialistes. L'objectif déclaré était de créer du lien social entre les groupes ethno-confessionnels et d'accélérer la bulgarisation des groupes minoritaires. On peut penser que l'on testait alors à petite échelle une seconde phase du Processus de régénération. 